\title{
Redução da altura de plantas de soja causada pelo ácido 2,3,5-triiodobenzóico
}

\author{
Height reduction in soybean plants caused by 2,3,5-triiodobenzoic acid
}

Stella Consorte Cato ${ }^{1}$ Paulo Roberto de Camargo e Castro ${ }^{2}$

\begin{abstract}
- NOTA -
RESUMO

O ácido 2,3,5-triiodobenzóico (TIBA), um inibidor do transporte de auxina, quando aplicado via foliar, pode reduzir o crescimento vegetativo. Um dos problemas ainda enfrentado pelos produtores de soja é o acamamento da cultura no campo devido a crescimento vegetativo excessivo. Objetivando avaliar os efeitos do TIBA sobre o desenvolvimento e a produção de plantas de soja (Glycine max (L.) Merrill cv. Pintado), realizou-se um experimento em casa de vegetação,

yield, an experiment was carried out in the greenhouse of the Department of Biological Sciences at ESALQ/USP. Using potted-plants, TIBA was sprayed on the leaves of soybean plants at 30, 40 and $50 \mathrm{~g} \mathrm{~L}^{-1}$, at V5 phenological stage. Plant height, number and mass of pods per plant and 100-grain mass were assessed. The experiment was completely randomized with 4 treatments and 6 replications. Data were submitted to variance analysis and polynomial regression. TIBA was effective in reducing plant height, without affecting parameters related to production.
\end{abstract} no Departamento de Ciências Biológicas da ESALQ/USP. Em plantas envasadas, aplicou-se TIBA, via foliar, nas concentrações de 30, 40 e $50 \mathrm{mg} \mathrm{L}^{-1}$, no estádio fenológico V5. Os parâmetros avaliados foram a altura das plantas, o número e a massa de vagens e grãos por planta e a massa de 100 sementes. O delineamento experimental foi inteiramente casualizado com quatro tratamentos e seis repetições. Os dados obtidos foram submetidos à análise de variância e regressão polinomial. Verificou-se redução significativa na altura de plantas de soja tratadas com concentrações crescentes de TIBA, quando comparadas ao controle. O TIBA foi eficaz em reduzir a altura de plantas de soja, sem afetar negativamente parâmetros relacionados à produção.

Palavras-chave: regulador vegetal; desenvolvimento vegetativo; frutificação; inibidores de auxina.

\section{ABSTRACT}

The 2,3,5-triiodobenzoic acid, an auxin transport inhibitor, when applied on leaves can reduce the vegetative growth. One of the problems faced by soybean producers is the lodging of the plants in the field due to excessive vegetative growth. Trying to evaluate the effects of TIBA over soybean (Glycine max (L.) Merrill cv. Pintado) vegetative growth and
Key words: plant regulator; vegetative growth; pod-set; auxin inhibitor.

Os componentes da produtividade da soja, tais como número de plantas por unidade de área, número de vagens por planta, número de sementes por vagem e massa média de sementes, são determinados por processos fenológicos como germinação, desenvolvimento vegetativo, florescimento, frutificação e maturação. Dentre os diversos fatores que podem afetar essas fases do desenvolvimento das culturas, os hormônios vegetais desempenham um papel importante, podendo uniformizar a germinação, controlar o desenvolvimento vegetativo, aumentar a fixação de flores e frutos e antecipar ou atrasar a maturação.

Um dos principais problemas enfrentados pelos produtores de soja é o intenso crescimento vegetativo, que provoca acamamento das plantas,

${ }^{1}$ Departamento de Produção Vegetal, Escola Superior de Agricultura "Luiz de Queiroz" (ESALQ), Universidade de São Paulo (USP), Caixa Postal 09, 13418-900, Piracicaba, SP, Brasil. E-mail: stellac@esalq.usp.br. Autor para correspondência.

${ }^{2}$ Departamento de Ciências Biológicas, ESALQ/USP, Piracicaba, SP, Brasil. 
dificultando e prejudicando a colheita. Esse fato ocorre em função de fortes adubações visando a incrementos na produção, de excesso de nitrogênio, de cultivar de excessivo crescimento indeterminado, de condições climáticas causadoras de turbidez atmosférica (precipitações continuadas e tempo nublado), além de espaçamento que promova alta densidade e competição por luminosidade, causando estiolamento, gasto de energia que poderia ter sido alocada para a produção de grãos (CASTRO, 2005 - Informe verbal).

Na maioria das plantas, o crescimento da gema apical inibe o crescimento das gemas axilares, fenômeno denominado de dominância apical. A auxina, hormônio sintetizado nos meristemas apicais e transportado em direção basípeta, é responsável por este fenômeno. Inibidores do transporte de auxina, como o ácido 2,3,5-triiodobenzóico (TIBA), podem eliminar a inibição das gemas axilares (TAIZ \& ZEIGER, 2004). O TIBA inibe o transporte polar basípeto da auxina por competir com este hormônio pelo mesmo sítio de ligação nas proteínas transportadoras, localizadas na membrana plasmática (GELDNER et al., 2001).

Segundo resultados mostrados por BURTON \& CURLEY (1966) e HICKS (1967), plantas de soja tratadas com TIBA desenvolveram grande número de ramos e folhas pequenas de coloração verdeintensa.

A influência do TIBA e da ethephon nas concentrações de 25, 50 e $75 \mathrm{~g} \mathrm{~L}^{-1}$, em duas épocas, no início e na metade do florescimento da cultura da soja, foi estudada por REZENDE et al. (1981). Independentemente das concentrações aplicadas, a pulverização na metade do florescimento promoveu maior produção de grãos, tanto nas plantas pulverizadas com TIBA como naquelas tratadas com ethephon. $\mathrm{O}$ TIBA aumentou, também, a germinação e o vigor das sementes.

Na Índia, em um experimento de campo com a cultura da soja, foram realizadas aplicações foliares de TIBA nas concentrações de 50 a $250 \mathrm{~L}^{-1}$. Os teores de clorofila e de nitrogênio nas folhas foram aumentados com a aplicação do biorregulador. A maior produção de sementes foi obtida com a concentração de $100 \mathrm{~L}^{-1}$ (DEOTALE et al., 1996). Resultados semelhantes foram obtidos por PANKAJ et al. (2001), em cujas pesquisas a aplicação de TIBA nas concentrações de 50 e $100 \mathrm{mg} \mathrm{L}^{-1}$ resultou em maior biomassa total na colheita e em maior produção de sementes.

Analisando-se a literatura, verifica-se que os efeitos do TIBA variam em função, principalmente, da concentração e do estádio fenológico em que é aplicado. Em função disso, este trabalho teve como objetivo verificar o efeito do TIBA, em diferentes concentrações, aplicado no estádio fenológico V5, sobre o desenvolvimento e a produção de plantas de soja.

O experimento foi realizado no Horto Experimental do Departamento de Ciências Biológicas da ESALQ/USP, em casa de vegetação, com plantas envasadas. A semeadura ocorreu em 19 de dezembro de 2002, colocando-se cinco sementes de soja do cultivar Pintado, o qual apresenta hábito de crescimento determinado e flores brancas, em vasos de 20 litros. A emergência ocorreu em 22 de dezembro de 2002. Após o desbaste, foram deixadas duas plantas por vaso.

O TIBA foi aplicado via foliar às concentrações de 30, 40 e $50 \mathrm{~g} \mathrm{~L}^{-1}$ em 17/01/2003, no estádio fenológico V5, quando as plantas apresentavam o quarto par de folhas trifolioladas completamente expandido. O controle não recebeu a aplicação do produto, sendo as plantas pulverizadas apenas com água.

O delineamento experimental foi inteiramente casualizado, com quatro tratamentos e seis repetições.

A altura das plantas foi determinada semanalmente aos 33, 40, 47 e 54 dias após as emergências (DAE) das plântulas, sendo que a última avaliação coincidiu com o estádio R1, quando o crescimento vegetativo de cultivares com hábito de crescimento determinado praticamente cessa. Os dados obtidos foram analisados seguindo-se o esquema fatorial $4 \mathrm{x} 4$, referente às quatro concentrações de TIBA e às quatro épocas de avaliação da altura. Após a colheita em 24/04/2003, determinou-se o número e a massa seca de vagens e grãos por planta e a massa de 100 grãos. Os dados obtidos foram submetidos à análise de variância e regressão polinomial, considerando-se o nível de $5 \%$ de probabilidade.

Nas quatro avaliações realizadas, aos 33, 40, 47 e 54 DAE, o TIBA, às concentrações de 30, 40 e $50 \mathrm{mg} \mathrm{L}^{-1}$, aplicado em plantas de soja no estádio fenológico V5 promoveu reduções significativas na altura das plantas (Figura 1).

Na última avaliação, aos 54 DAE, quando as plantas de soja estavam em R1, a menor concentração do regulador vegetal, 30mg $\mathrm{L}^{-1}$, foi suficiente para promover uma redução da ordem de $54 \%$ na altura das plantas tratadas, quando comparadas às do controle.

Resultados semelhantes foram obtidos por outros autores, que verificaram diminuição no crescimento vegetativo da soja, com redução no comprimento dos entrenós de plantas tratadas com TIBA(GLAPP JÚNIOR, 1973; GREER e ANDERSON, 1965).

A análise de variância revelou que os demais parâmetros, o número e a massa de vagens e grãos e a massa de 100 grãos, não foram influenciados pela aplicação do TIBA (Tabela 1). 


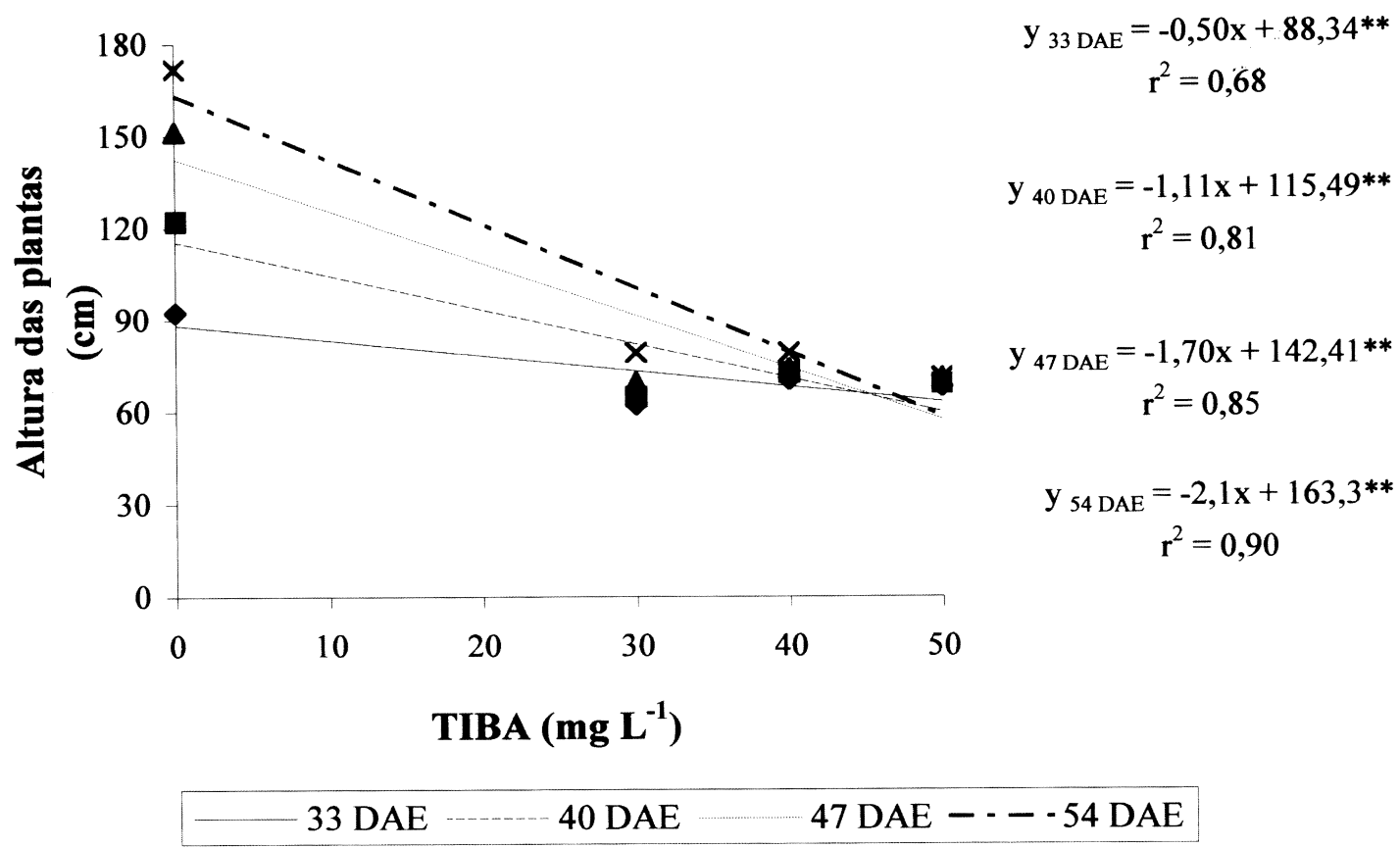

**significativo ao nível de $1 \%$ de probabilidade.

Figura 1 - Alturas de plantas de soja tratadas com o ácido 2,3,5-triiodobenzóico (TIBA), nas concentrações de 0, 30, 40 e 50 mg L-1, determinadas aos 33, 40, 47 e 54 dias após a emergência.

Tabela 1 - Parâmetros relacionados à produção de plantas de soja tratadas com o ácido 2,3,5-tiiodobenzóico (TIBA) no estádio fenológico V5.

\begin{tabular}{|c|c|c|c|c|c|}
\hline TIBA $\left(\mathrm{mg} \mathrm{L}^{-1}\right)$ & $\mathrm{N}^{\circ}$ vagens & Massa seca vagens (g) & $\mathrm{N}^{0}$ grãos & Massa seca grãos (g) & Massa seca 100 grãos (g) \\
\hline 0 & 94 & 39,8 & 336 & 52,0 & 15,4 \\
\hline 30 & 93 & 37,2 & 291 & 42,2 & 14,3 \\
\hline 40 & 78 & 36,5 & 259 & 37,3 & 14,3 \\
\hline 50 & 94 & 32,3 & 242 & 33,6 & 13,9 \\
\hline $\mathrm{CV}(\%)$ & 35,5 & 41,5 & 30,9 & 35,9 & 12,3 \\
\hline
\end{tabular}

Os resultados obtidos mostraram que o TIBA aplicado no início do desenvolvimento da soja, em V5, nas concentrações de 30,40 ou $50 \mathrm{mg} \mathrm{L}^{-1}$, foi eficiente em reduzir a altura das plantas, sem influenciar negativamente os parâmetros relacionados à produção.

\section{AGRADECIMENTOS}

Ao Conselho Nacional de Desenvolvimento Científico e Tecnológico (CNPq), pela concessão de bolsa ao pesquisador Cato.

\section{INFORME VERBAL}

CASTRO, P.R.C. Depto de Ciências Biológicas, ESALQ/USP, Caixa Postal 09, 13418-900, Piracicaba, SP, Brasil. E-mail: prccastro@esalq.usp.br.

\section{REFERÊNCIAS}

BURTON, J.C.; CURLEY, R.L.A. Influence of triiodobenzoic acid on growth, nodulation and yield of inoculated soybean. Agronomy Journal, v.58, p.406-408, 1966.

DEOTALE, R.D. et al. Effect of TIBA and B-nine on growth parameters, biochemical aspects and yield of soybean. Journal of Soils and Crops, v.6, n.1, p.89-93, 1996.

GELDNER, N. et al. Auxin transport inhibitors block PINT cycling and vesicle trafficking. Nature, n.413, p.425-428, 2001.

GLAPP JUNIOR, J.G. Response of 'Bragg' soybean to TIBA. Agronomy Journal, v.65, p.41-43, 1973. 
GREER, H.A.L.; ANDERSON, I.C. Response of soybean to triiodobenzoic acid under field conditions. Crop Science, v.5, p.229-232, 1965.

HICKS, D.R. Response of soybeans to TIBA (2,3,5triiodobenzoic acid) and high fertility levels. Crop Science, v.7, p.397-398, 1967.

PANKAJ, K. et al. Studies on foliar application of growth regulators on biomass production, harvest index and yield of soybean (Glycine max (L.) Merrill). Annals of Agricultural Research, v.22, n.2, p.221-224, 2001.
REZENDE, P.M. et al. Efeitos de TIBA e Ethrel aplicados em diferentes épocas e doses sobre a produção e características da semente de soja (Glycine $\max (\mathrm{L})$ Merrill). In: SEMINÁRIO NACIONAL DE PESQUISA DE SOJA, 2., 1981, Brasília, DF. Anais... Brasília: Centro de Pesquisa Agropecuária dos Cerrados - Embrapa, 1981. V.1, p.193-201.

TAIZ, L.; ZEIGER, E. Fisiologia vegetal. Porto Alegre: Artmed, 2004. 719p. 